\title{
Biologia reprodutiva de Astyanax scabripinnis paranae (Eigenmann) (Ostheichthyes, Characidae), do ribeirão das Marrecas, bacia do rio Tibagi, Paraná
}

\author{
Angela Maria Louzada Veregue ${ }^{1} \&$ Mário Luís Orsi ${ }^{1}$ \\ ${ }_{1}$ Departamento de Biologia Animal e Vegetal, Universidade Estadual de Londrina. Caixa postal 6001, 86051-990 Londrina, \\ Paraná, Brasil. E-mail: orsi@uel.br
}

\begin{abstract}
Reproductive biology of Astyanax scabripinnis paranae (Eigenmann) (Ostheichthyes, Characidae) from Marrecas creek of the Tibagi basin, Paraná. Some aspects of the reproductive cycle of female "lambari", Astyanax scabripinnis paranae (Eigenmann, 1927) were studied. The specimens were collected in intervals of fifteen days, from September 1979, until November 1980, in the Marrecas creek (Irerê and Paiquerê districts), Londrina, Paraná, Brazil. The maturity scale was characterized in five stages: immature, maturation, spawning, spent, and resting, which was established by the gonad-somatic relation and the ovary morphology and microscopic aspects. The maturation curve and distribution of maturity stages show that the period of reproduction is very long; spawning extended from July to March. The gonad cycle is related to seasons: maturation occurs chiefly in the winter months, spawning specimens are found in spring and summer, and those in rest are frequent in autumn. In the first sexual maturation the medium length of females was $5.04 \mathrm{~cm}$. Also was observed more males than females during all collecting periods.
\end{abstract}

KEY WORDS. Astyanax scabripinnis, Characidae, biology, reproduction, Tibagi river.

O lambari Astyanax scabripinnis paranae (Eigenmann, 1927), pertencente à família Characidae, é uma das espécies da subfamília Tetragonopterinae que representam um dos grupos mais importantes de espécies de peixes no Brasil (BRITSKI 1972). O gênero Astyanax (Linneaus, 1758) é compreendido por espécies que ocupam os mais diversos habitats nas bacias hidrográficas brasileiras (GARUTTI \& BRITSKI 2000).

Astyanax scabripinnis (Eigenmann, 1907) vem sendo considerada uma espécie típica das cabeceiras dos rios, riachos e ribeirões (BRITSKI 1972). No Paraná, tal fato é corroborado pelas capturas dessa espécie efetuadas pela equipe de ictiologia da Universidade Estadual de Londrina (UEL), geralmente em pequenos mananciais, sendo, a maioria das capturas, em áreas de cabeceira que apresentam águas correntes entre remansos, o que evidencia a importância de A. scabripinnis nesses ambientes, os quais naturalmente apresentam grandes oscilações nas suas condições ambientais e hidrológicas.

Astyanax scabripinnis paranae, redescrita por GoDoy (1975), apresenta coloração amarelo-alaranjada em quase todo o corpo, sendo o dorso mais escurecido. A mancha umeral também é escura, tem forma triangular irregular e a base voltada para o dorso. Uma faixa prateada percorre a lateral do corpo, escurecendo à medida que se aproxima da região do pedúnculo.
Os caracteres merísticos importantes em sua identificação são quatro dentes usualmente presentes na série externa do prémaxilar, de um a sete dentes no maxilar, nadadeira anal contendo entre 17 e 23 raios e altura correspondendo a 2,6-3,6 vezes seu comprimento total (EIGENMANN 1921).

Diversos autores estudaram espécies de Astyanax, dentre eles Nomura (1975), Agostinho et al. (1984), Barbieri (1992), Barbieri et al. (1996), Lobón-CERVIÁ \& BeNNEMANN (2000), GarutTi $\&$ Britski (2000) e Maistro et al. (2001), mas a maioria dos estudos direcionados ao grupo A. scabripinnis está relacionada a parâmetros de parasitismo e questões citogenéticas, que o caracterizam como um complexo de citótipos (Moreira-FilHo \& Bertollo 1991; Souza \& Moreira-Filho 1995; Porto-Foresti et al. 1997; Mizoguchi \& Martins-SANTOs 1998; Maistro et al. 2000), e raros são os estudos referentes à sua biologia reprodutiva. Em razão de sua ampla distribuição em vários ribeirões da bacia do rio Tibagi e da ausência de informações sobre sua biologia, este estudo foi realizado com o intuito de conhecer os processos reprodutivos de Astyanax scabripinnis paranae do ribeirão das Marrecas. Apesar de ser um estudo de cunho descritivo, os resultados obtidos ampliam o conhecimento biológico dos lambaris presentes na bacia hidrográfica do rio Tibagi e possibilitam subsídios que denotam a importância ecológica da espécie e do grupo nos ambientes que ocupam. 


\section{MATERIAL E MÉTODOS}

As coletas dos espécimes foram realizadas no ribeirão das Marrecas, afluente de pequena ordem e extensão da margem direita do rio Tibagi, um dos principais rios do Sul do país. Esse ribeirão se localiza na região do município de Londrina, no estado do Paraná. Foram escolhidos dois trechos de coleta ao longo de sua extensão, com aproximadamente $4 \mathrm{~km}$ de distância entre eles (Fig. 1). O primeiro trecho localiza-se no distrito de Irerê (coordenadas $51^{\circ} 07^{\prime} 05^{\prime \prime} \mathrm{W}$ e $23^{\circ} 29^{\prime} 01^{\prime \prime} \mathrm{S}$ ), a 520 $\mathrm{m}$ de altitude. Apresenta fundo rochoso e lajeado, pequenas quedas d'água com poços e é marginado por vegetação ciliar arbustiva. O segundo trecho localiza-se no distrito de Paiquerê, a jusante do primeiro (coordenadas $51^{\circ} 05^{\prime} 04^{\prime \prime} \mathrm{W}$ e $23^{\circ} 35^{\prime} 11^{\prime \prime} \mathrm{S}$ ), a $470 \mathrm{~m}$ de altitude. Suas características principais são o fundo lodoso, vegetação marginal arbórea (mata primária) na margem direita e vegetação marginal arbustiva na margem esquerda.

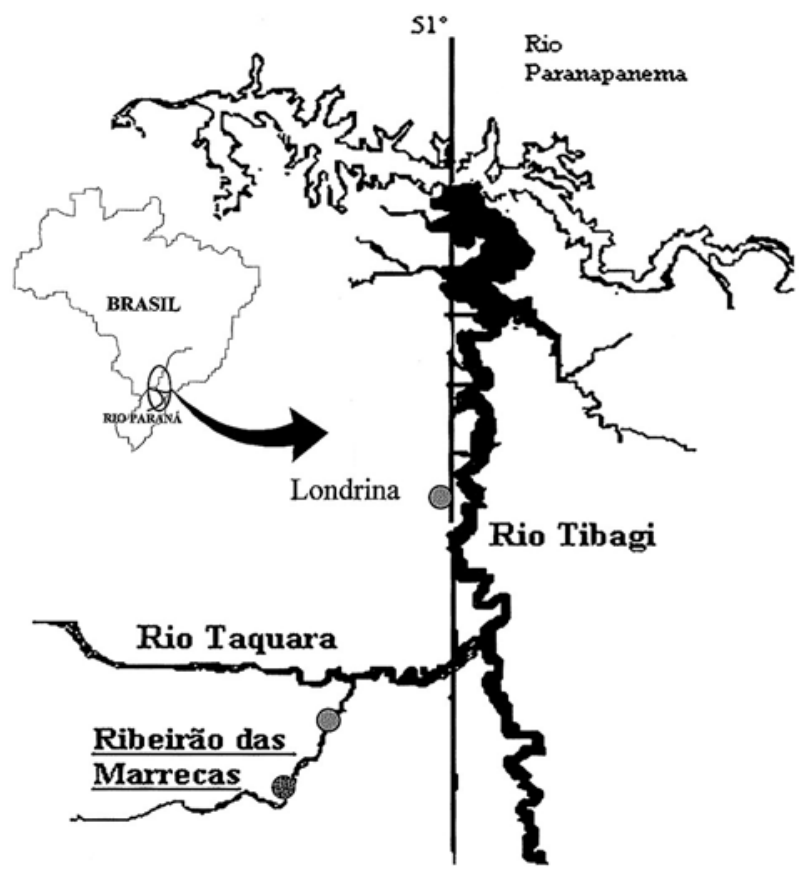

Figura 1. Mapa da área de coleta, com as indicações (pontos em cinza) dos locais de coleta de $A$. scabripinnis no ribeirão das Marrecas.

Para o esforço de captura dos espécimes foram utilizadas tarrafas com malha de $1,2 \mathrm{~cm}$ entre nós, e peneiras com malha de $0,3 \mathrm{~cm}$ de diâmetro para captura de jovens. As coletas foram realizadas quinzenalmente, no período compreendido entre setembro de 1979 e novembro de 1980.

Os espécimes capturados tiveram seus dados biológicos referentes ao peso total em gramas (aproximação em miligramas) e ao comprimento total em centímetros (aproximação em milímetros) obtidos em laboratório da UEL. Os exemplares de testemunha taxonômica foram depositados na coleção zoológica do Museu de Zoologia do Departamento de Biologia Animal e Vegetal da UEL.

Para a determinação do sexo, foi feita a análise macroscópica das gônadas, avaliando-se parâmetros como cor, transparência, vascularização e visualização de ovócitos a olho nu. Tomou-se, também, o peso das gônadas em gramas (com aproximação em miligramas). Posteriormente à pesagem, algumas das gônadas foram fixadas em Bouin, para estudo microscópico. Na obtenção dos cortes histológicos das gônadas foram utilizadas técnicas histológicas padrão para esse tipo de estudo e feita a sua coloração com hematoxilina-eosina (Lison 1960).

Para a análise dos dados biológicos fez-se a determinação da proporção sexual mensal dos espécimes, aplicando-se o teste $X^{2}$ para determinação de diferenças significativas. A escala de maturidade foi obtida usando-se as características macro e microscópicas das gônadas de fêmeas. As gônadas foram determinadas com base nas fases de desenvolvimento dos ovócitos, nas modificações das estruturas celulares e nas afinidades por corantes.

Foi verificada mensalmente a distribuição da freqüência de estádios de maturação das fêmeas e foi aplicado o teste $X^{2}$ utilizando-se probabilidade de $95 \%$. Como forma auxiliar de análise dos estádios, foi realizado o cálculo da relação gonadossomática (RGS) de cada fêmea, e os valores médios mensais foram aplicados para estabelecer a curva de maturação e, assim, obter a época de desova.

O estudo para a determinação do tamanho da primeira maturação sexual foi realizado segundo metodologia proposta por VAzzoler (1996). Paras as fêmeas adultas, foram feitas as distribuições de freqüências relativas por classes de comprimento de $0,5 \mathrm{~cm}$, aplicando-se o teste $t$ de Student para comparação com a fêmea de menor tamanho em reprodução. Dados sobre a proporção de jovens e adultos agrupados também foram obtidos mensalmente.

\section{RESULTADOS}

No que se refere à morfologia das gônadas, A. scabripinnis paranae apresentou estruturas pares e saculiformes e as gônadas situadas dorsalmente na cavidade geral do corpo, relacionadas lateralmente com a bexiga natatória e separadas entre si, fusionando-se em sua parte caudal, nas proximidades do poro genital. Externamente, as gônadas são revestidas pelo peritônio visceral e ligadas ao dorso da cavidade abdominal através do mesovário.

Com base em escalas de maturidade já utilizadas em outras espécies e modificado a partir dos aspectos analisados de A. scabripinnis paranae, foram empregados cinco estádios e suas características, como segue:

Estádio I. Imaturo: nessa fase as gônadas apresentavamse filiformes, pequenas, com alargamento terminal (porção cefálica), coloração levemente rosada, não sendo observados ovócitos e irrigação; as secções histológicas mostravam ovócitos e ovogônias ocupando virtualmente toda a extensão do corte, pequenos e com núcleo grande circundado por citoplasma delgado levemente basófilo. O nucléolo era grande e, geralmente, único; os ovócitos tinham tamanhos variados, forma esférica e poligonal (Fig. 2).

Estádio II. Repouso: nessa fase as gônadas apresentavamse ligeiramente alargadas, ocupando pequeno espaço da cavidade abdominal; eram incolores, transparentes, gelatinosas, 

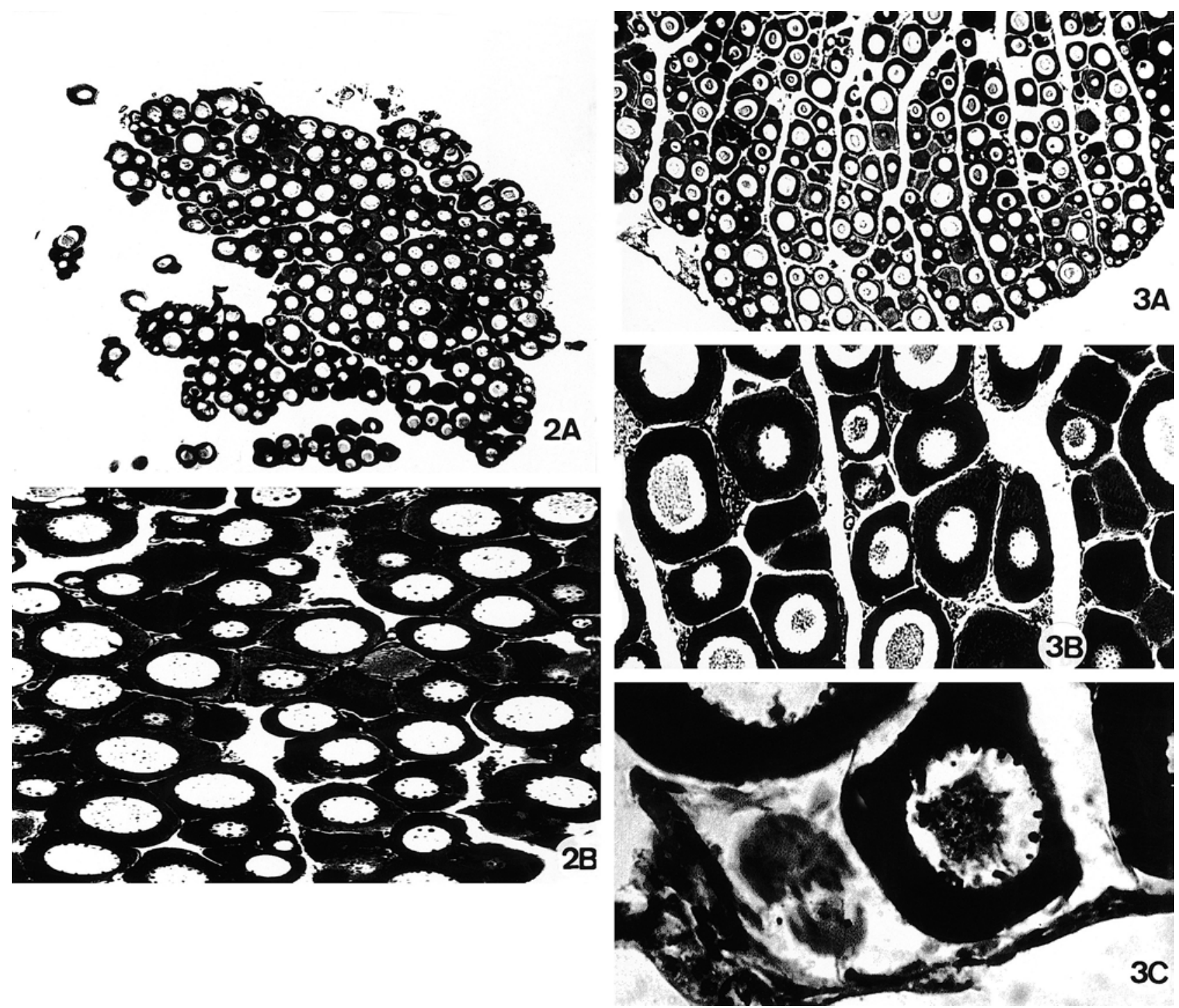

Figuras 2-3. Corte transversal das gônadas: (2) no estádio imaturo, seta indica o grande núcleo nos ovócitos de diversas formas; (3) no estádio de repouso, (A) seta indica a disposição dos ovócitos em lamelas, (B) detalhe da lamela mostrando ovócitos basófilos e poligonais, (C) detalhe da lamela mostrando as ovogônias com nucléolos numerosos e periféricos.

sem irrigação evidente e os ovócitos não eram visíveis a olho nu. Havia predomínio de ovócitos poligonais organizados em lamelas que se projetavam da parede das gônadas e fortemente basófilos, com núcleo relativamente grande, nucléolos numerosos e periféricos; algumas ovogônias foram observadas (Fig. 3).

Estádio III. Maturação: nessa fase as gônadas eram mais volumosas, apresentavam irrigação mediana longitudinal e poucas ramificações, coloração variando do laranja ao brancoacinzentado; os ovócitos eram visíveis a olho nu e apresentavam diversos tamanhos. Além dos ovócitos descritos no estádio II, havia ovócitos maiores, que apresentavam citoplasma com basofilia moderada, grande numero de vesículas periféricas e nucléolos em grande número; havia, também, ovócitos ainda maiores, com deposição de grânulos de vitelo em extensões variáveis (Fig. 4). Estas últimas células predominavam no final deste estádio.

Estádio IV. Desovando: nessa fase as gônadas apresentavam-se largas, muito volumosas, ocupavam quase toda a cavidade visceral e a vascularização era intensa e cor pardo-esverdeada; os ovócitos eram grandes e abundantes; na extensão das gônadas apareceram espaços gelatinosos, principalmente nas fêmeas que já haviam eliminado muitos ovócitos, os quais, além de grandes, eram repletos de vitelo, 

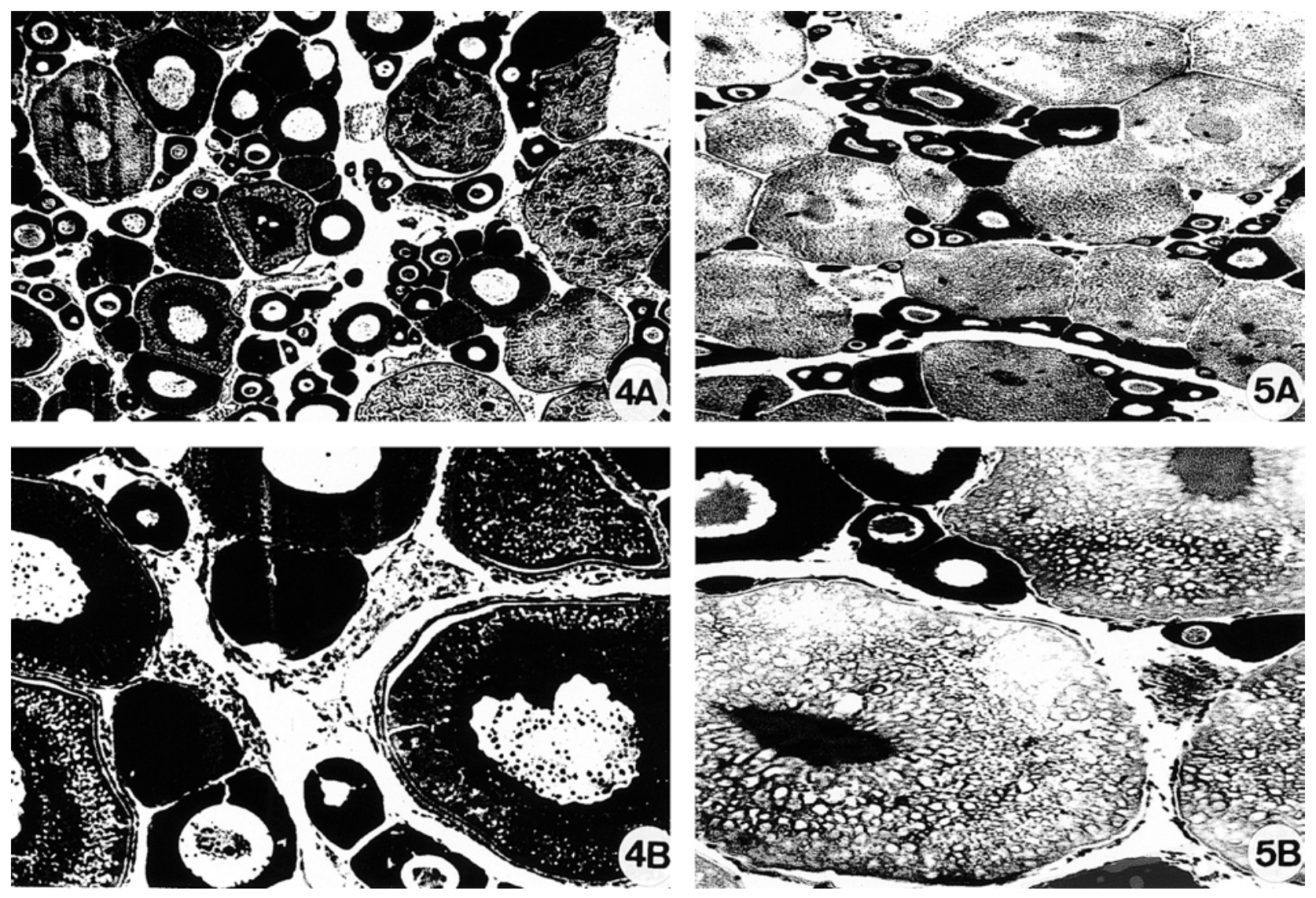

Figuras 4-5. Corte transversal de gônadas: (4) no estádio maturação, (A) seta indica ovócitos de tamanhos variados, (B) detalhe indicado pela seta mostra ovócito com citoplasma de basofilia moderada e grânulos de vitelo; (5) no estádio desovando, (A) ovócitos grandes, tendo nos interstícios (seta), ovócitos poligonais, (B) detalhe indicado pelas setas mostra ovócitos com citoplasma repleto de vitelo e núcleo amorfo.

tinham o núcleo amorfo e ocupavam quase todo o ovário. Havia ovócitos poligonais, similares aos do estádio II (repouso), preenchendo os interstícios deixados pelas células anteriores. Foram observados, também, folículos vazios (Fig. 5).

Estádio V. Esgotado: nessa fase as gônadas eram flácidas, apresentavam muitas manchas sangüíneas, cor marromavermelhada e alguns ovócitos grandes, mergulhados em sua matriz e de aspecto gelatinoso, e seu volume era notavelmente reduzido. Alguns ovócitos eram grandes, repletos de vitelo e continham grande número de ovócitos vitelinados em absorção (Fig. 6).

$\mathrm{Na}$ análise da freqüência relativa mensal dos quatro estádios de maturidade foi possível detectar a presença de fêmeas no estádio de maturação no período de abril a agosto (Fig. 7). Indivíduos desovando foram registrados de setembro a março, e valores mais elevados em agosto, setembro e outubro de 1980. Fêmeas esgotadas estiveram presentes de outubro a abril; indivíduos em repouso foram observados de forma intermitente durante todo o ano, com maiores percentuais entre março e junho.
Para a curva de maturação (Fig. 8), os resultados obtidos indicaram valores crescentes da relação gonadossomática ocorrendo de julho a setembro, com o valor máximo em setembro. Os valores decresceram de outubro de 1979 a março de 1980, entrando em valores mínimos até junho.

$\mathrm{Na}$ figura 9, que se refere ao tamanho de primeira maturação, percebe-se que $50 \%$ das fêmeas de A. scabripinnis paranae apresentaram gônadas iniciando o processo de maturação com 5,04 cm de comprimento total. Comparando-se esse dado com o tamanho da menor fêmea adulta em reprodução, que apresentou $4,7 \mathrm{~cm}$ de comprimento, verifica-se que não ocorreram diferenças estatísticas significativas quando aplicado o teste $t$ de Student. Todos os peixes que apresentaram tamanhos superiores a $7,0 \mathrm{~cm}$ apresentavam-se maduros sexualmente (adultos). A equação matemática da transformação linear da curva de maturação foi $\mathrm{Y}=5,0321 \mathrm{X}-8,3616\left(\mathrm{R}^{2}=\right.$ 0,9831). A observação de jovens e adultos nas capturas (Fig. 10) possibilitou detectar a presença de jovens em menor valor, mas estes estiveram presentes em todo o período de estudo, ocorrendo um aumento acentuado dos valores nos meses de 

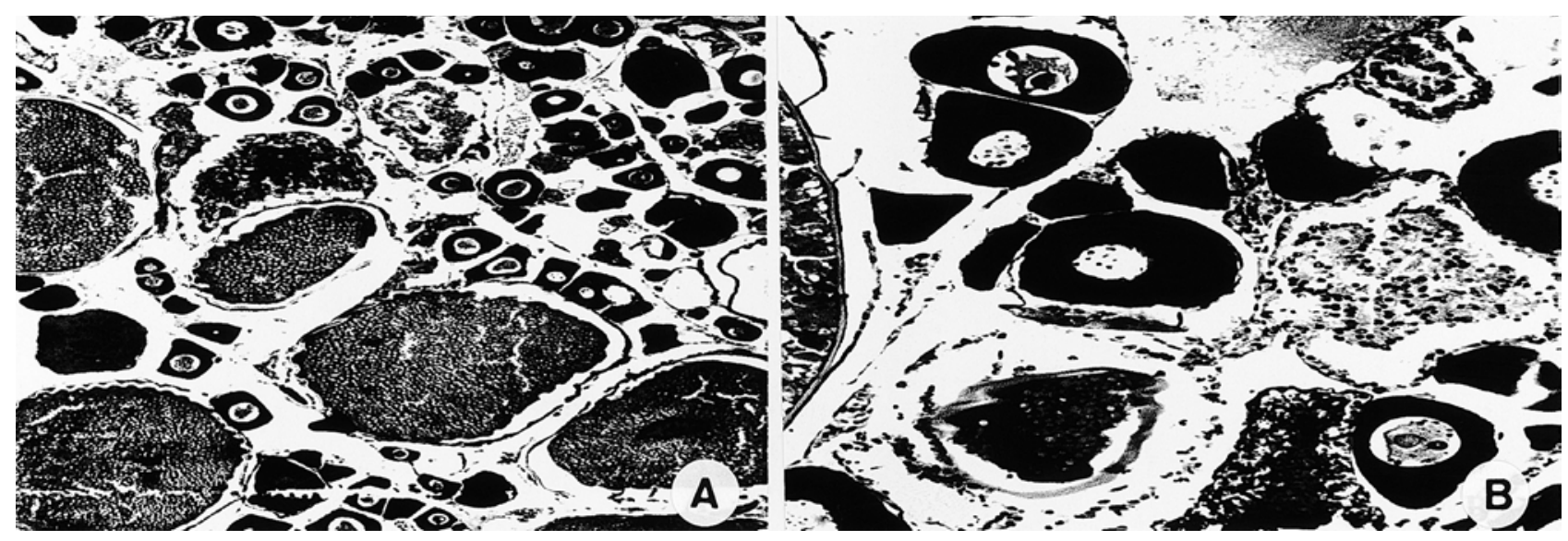

Figura 6. Corte transversal de gônadas no estádio esgotado. (A) Ovócitos grandes indicados pela seta com vitelo e ovócitos de citoplasma basófilo, (B) detalhe indicado pelas setas mostrando ovócitos vitelinados em reabsorção e folículo vazio.

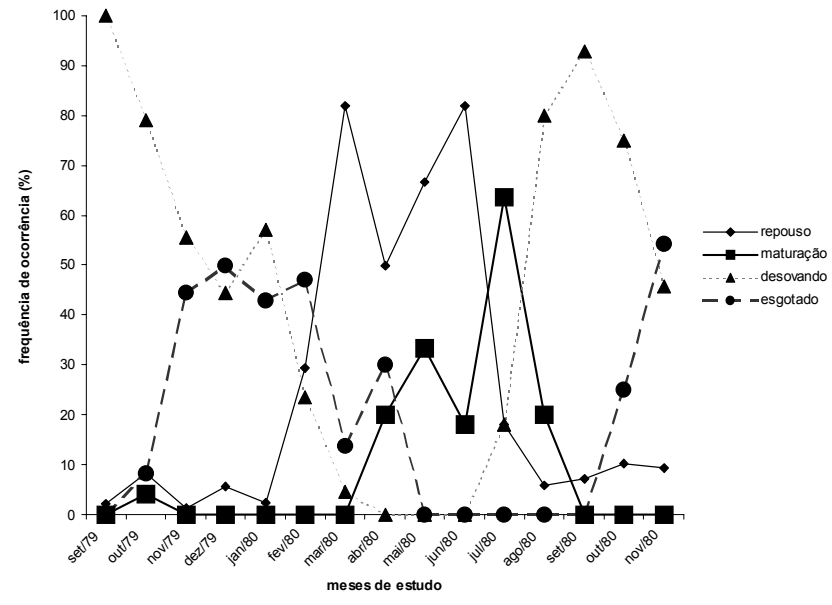

Figura 7. Distribuição de freqüências percentuais dos estádios de maturação gonadal de $A$. scabripinnis paranae durante o período de setembro de 1979 a novembro de 1980.

setembro de 1979 e outubro de 1980, com uma baixa nos valores da RGS média obtida

A distribuição das freqüências percentuais agrupadas mensalmente para proporção sexual (Fig. 11) demonstra que os machos predominaram na maioria dos meses do período estudado, com exceção de abril, o mesmo se verificando para o total agrupado do período de coletas, com diferença estatística significativa entre os sexos, $X^{2}$ (crítico) $=3,84$, significante a 0,05

\section{DISCUSSÃO}

As gônadas de $A$. scabripinnis paranae assemelham-se, em seu padrão geral, às demais espécies da família Characidae (Nomura 1975; Barbieri 1992; Bazzoli et al. 1998), e as

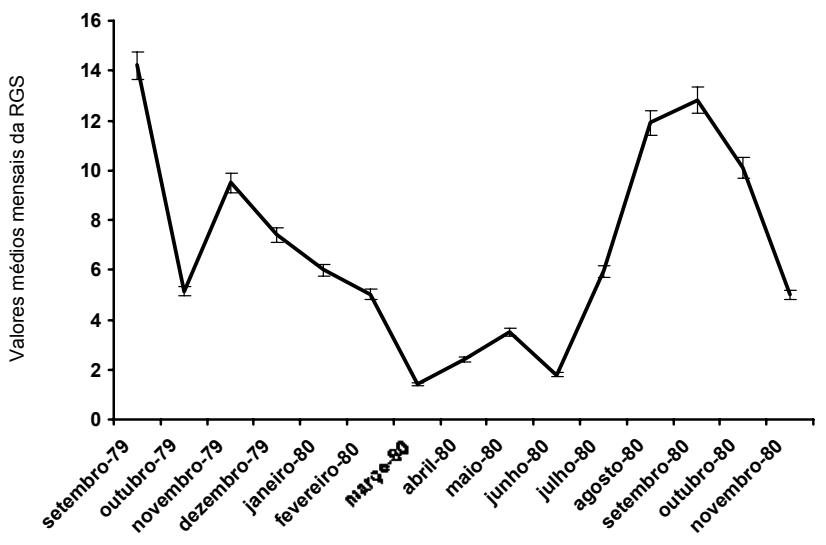

Meses de estudo

Figura 8. Valores médios mensais da relação gonadossomática (RGS) de fêmeas de $A$. scabripinnis paranae de setembro de 1979 a novembro de 1980 .

características mais específicas são semelhantes a outras espécies do gênero (Bazzoli et al. 1998), o que pode ser indicativo de que ocorrem padrões de táticas reprodutivas semelhantes nesse grupo de peixes, e que provavelmente estejam envolvidas no sucesso dos lambaris em ocupar os mais diversos habitats, como citado por GarutTI \& BRITSKi (2000) e WinemiLler (1989).

As gônadas e os testículos de indivíduos jovens dessa espécie (estádio I) são distinguíveis pela coloração levemente rosada dos primeiros e esbranquiçada dos segundos. Entretanto, esses critérios nem sempre são suficientes para distinguir um sexo do outro, o que às vezes traz a necessidade de se utilizar outros recursos, como exame das gônadas em microscópio estereoscópico ou de preparações histológicas das mesmas, fato já abordado por Vazzoler (1996), que ressaltou, em seus estudos, 


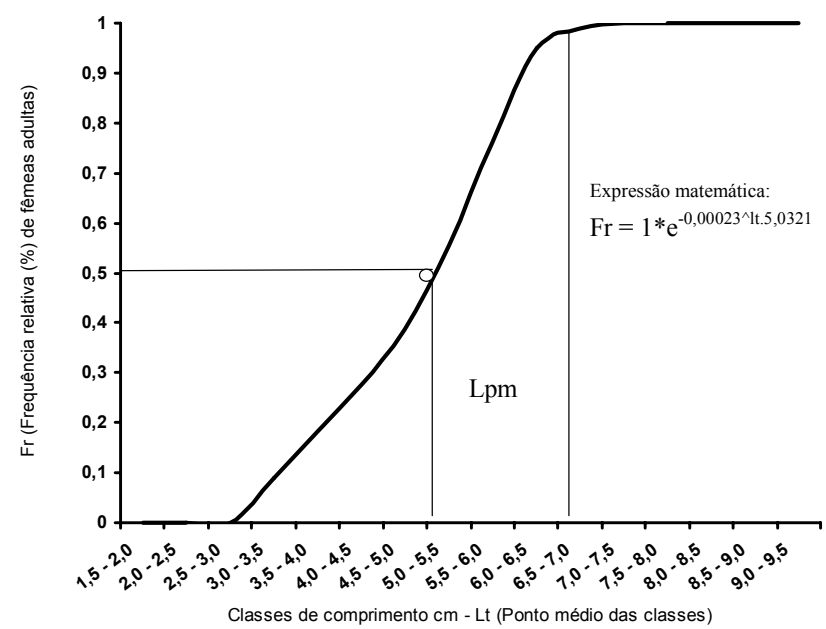

Figura 9. Distribuição percentual de fêmeas maduras de $A$. scabripinnis paranae por classe de comprimento. Lpm corresponde ao comprimento da primeira maturação para o período 19791980.

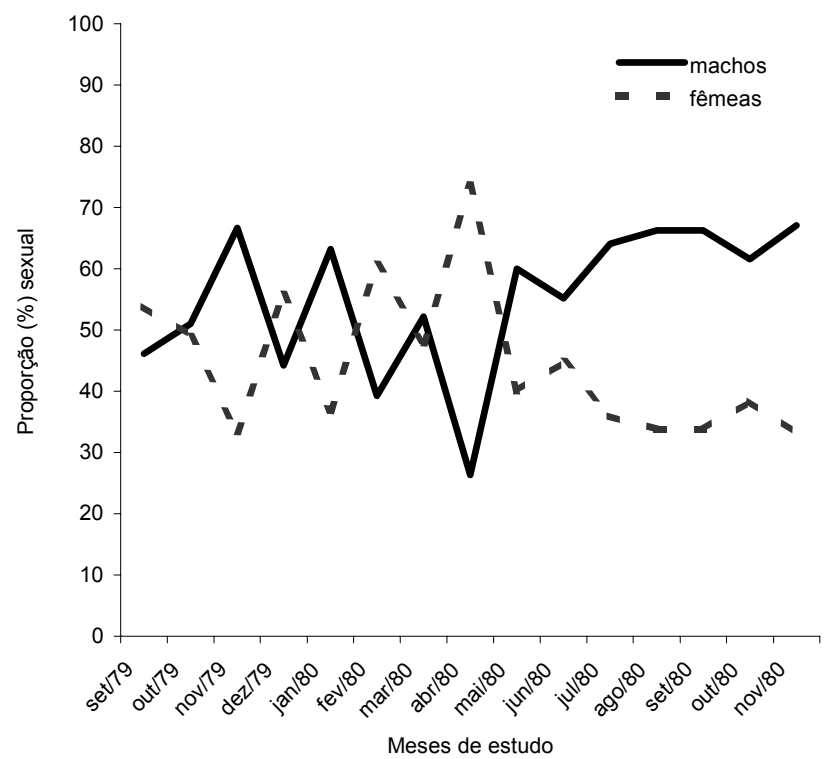

Figura 10. Distribuição da freqüência relativa de jovens e adultos de $A$. scabripinnis paranae capturados nos dois trechos de coleta no período 1979-1980.

que em determinadas situações há necessidade de se fazer uso de várias ferramentas de análise para conclusões mais confiáveis sobre a determinação correta do sexo, principalmente em peixes jovens.

Neste estudo, a escala de maturidade das gônadas utilizada desempenhou importante papel na descrição dos

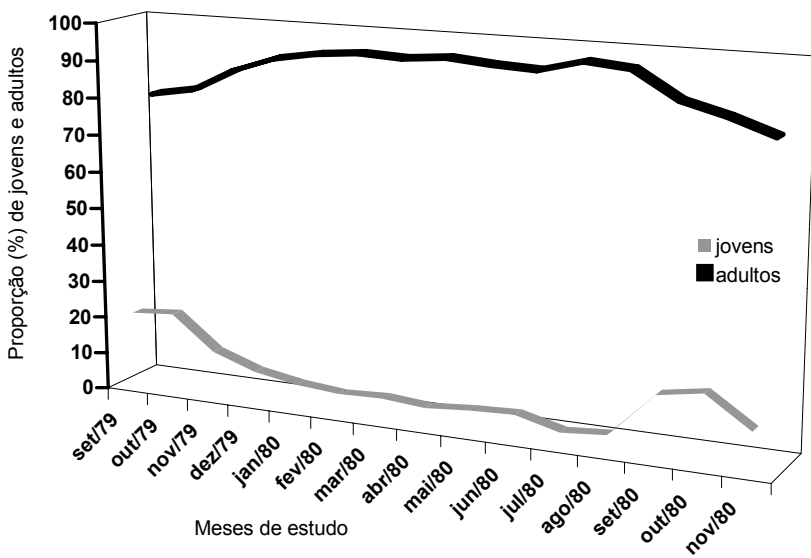

Figura 11. Distribuição mensal das freqüências percentuais de machos e fêmeas de A. scabripinnis paranae no período 1979-1980.

fenômenos do ciclo reprodutivo abordados para a espécie, situação já observada e evidenciada por VAzzoler (1996) e DiAS et al. (1998). A inclusão de uma escala baseada em critérios macro e microscópicos para a espécie $A$. scabripinnis paranae complementou de forma satisfatória os resultados e possibilitou fazer inferências a respeito de sua reprodução. Os cinco estádios de maturação foram evidentes e aplicados na tentativa de evitar erros decorrentes da pequena dimensão das gônadas, e para conferir à escala uma maior aplicabilidade e rapidez.

Para se compreender o uso que uma determinada espécie de teleósteo faz de uma área ou de um sistema, a identificação correta do estado reprodutivo dos indivíduos que os ocupam é essencial, pois fornece informações sobre a proporção de ocupação da área ou do sistema por jovens ou adultos e sobre os processos de desenvolvimento reprodutivo que denotam o esforço de sobrevivência da população.

Corroborando os resultados obtidos neste estudo, Dias et al. (1998) ressaltam que a utilização de escalas simplificadas de classificação das gônadas, com reduzido número de estádios, é mais viável e reduz sensivelmente a possibilidade de erros, principalmente em estudos que envolvem várias populações.

A análise microscópica de gônadas no estádio II (indivíduos aptos à primeira maturação e que já sofreram a desova) mostrou, além de ovogônias, ovócitos poligonais de citoplasma basófilo. As ovogônias são classificadas como "perinucleolar inicial" por Davis (1977). BAzzoli et al. (1998), entre outros autores, sugerem que nessa fase pode ocorrer proliferação de ovogônias, o que pode ser um indicativo de desova parcelada, onde lotes-reserva estariam sendo formados. Porém, nas gônadas do estádio II (repouso) não foi possível observar, a olho nu, a presença de ovócitos.

No estádio III (maturação), as características macroscópicas observadas na espécie foram semelhantes às propostas por Nomura (1975), Garutti (1989) e Braga (1990) para as espécies de lambaris por eles estudadas, principalmente quanto à coloração. A presença de óvulos de diferentes tamanhos nesse estádio corrobora as observações de VAzzoLER (1996), sendo, possivelmente, uma característica inerente dessa fase de desenvolvimento das gônadas; além disso, ocorrem muitos ovócitos em 
vitelogênese, compreendendo a fase real da atividade de formação dos grânulos vitelínicos que se fusionam no final do estádio, como já observado no estudo de WEST (1990).

Devido às dificuldades práticas encontradas na determinação dos estádios, o estádio IV (desovando) foi proposto para que se pudesse detectar se os indivíduos maduros já haviam eliminado os ovócitos ou não. A descrição macroscópica desse estádio não é, entretanto, muito diferente daquelas feitas para o estádio maduro de outras espécies de Astyanax estudadas (Garutti 1989; Genari-Filho \& Braga 1996). Outra semelhança observada, foi um padrão comum na forma e na disposição dos ovócitos desse estádio (IV).

As gônadas esgotadas têm aspecto macroscópico similar ao relatado para outros Astyanax, como já citado, com pequenas variações na coloração, que podem ter sido decorrentes de diferenças específicas ou talvez devido aos limites que a técnica empregada pode apresentar nesse tipo de qualificação. Com o decorrer do tempo, as gônadas esgotadas ingressaram no estádio II (repouso), perdendo a cor marrom-avermelhada, e foram observados várias células germinativas jovens e ovócitos que aparentemente eram de estoque, indicando uma reorganização das gônadas (VAZzolER 1996).

Em relação à curva de maturação obtida e à distribuição das freqüências de estádios, ficou evidente um período de maturação de abril a agosto, que pode ser considerado próprio da espécie nas condições ambientais vigentes no período de estudo Estudos feitos com outras espécies de Astyanax, como o de Vazzoler et al. (1997), corroboram esta colocação. Como a maioria das espécies de Astyanax, A. scabripinnis paranae parece ter uma periodicidade pronunciada em seu processo reprodutivo. No entanto, como os fatores ambientais não foram analisados em conjunto com as análises biológicas, não se pode afirmar quais condições do ambiente, naquele período, foram as condicionantes do processo, como fatores preditivos e terminais da reprodução.

A evidência de que a espécie apresentou uma desova de período longo leva a considerar que isso seja uma estratégia eficaz na produção da futura prole, pois aumenta as chances de perpetuação da espécie, ainda mais se considerarmos que o fato ocorreu em um ambiente de grande oscilação das condições hidrológicas (como é comum nos ribeirões).

Corroborando ao proposto para essas situações de estudos hidrológicos em riachos e ribeirões, como os realizados por RinCón (1999), UiedA (1984) e WootTon (1998), que constataram essa situação variável e, também, várias estratégias de vida dos peixes nesses ambientes.

A presença de indivíduos no estádio II (repouso) durante todo o período de estudo reforça essa idéia e caracteriza um grande esforço dessa população na alocação de energia para a reprodução, podendo desencadear efeitos ecológicos e biológicos em todo o ciclo de vida da espécie (BALON 1984). A presença de jovens durante todo o período de estudo corrobora essa observação, denotando um recrutamento eficaz da espécie.

A determinação do tamanho da primeira maturação, além de ajudar na tomada de medidas preservacionistas, permite o esclarecimento de importantes fatores da dinâmica de populações. Entre esses fatores está a representatividade genética nas gerações futuras, proporcionada pela eficiência na reprodução, que se relaciona diretamente ao tamanho em que a espécie entra em maturação reprodutiva e às condições que estabelecem esse processo (BEgon \& Mortimer 1990).
No ribeirão das Marrecas, A. scabripinnis apresentou um padrão de tamanho de primeira maturação de valor baixo em relação ao tamanho máximo que a espécie pode atingir, mas considerado precoce se comparado a outras espécies de Astyanax citados na literatura (BARBIERI et al. 1982, ArCiFA et al. 1991, Genari-Filho \& BRAga 1996).

O tamanho de primeira maturação observado pode ser inerente da espécie, caracterizando um padrão específico. Mas, tendo por base observações das características ambientais do ribeirão no período de estudo, pode-se inferir a esse parâmetro biológico possivelmente como uma resposta às condições ambientais vigentes naquele momento, considerando-se um tamanho pequeno; no entanto, este fato pode ter proporcionado vantagens reprodutivas à espécie (como o aumento da prole, por exemplo).

A proporção sexual clássica entre peixes é $50 \%$ de machos e 50\% de fêmeas (NiкOLSKY 1969). No entanto, A. scabripinnis apresentou, predominantemente, indivíduos machos na maioria dos meses. É possível que essa tática ocorra em virtude do seu comportamento reprodutivo, e possivelmente se relaciona a fatores de fecundidade das fêmeas. Corroborando essa constatação, WootTon (1998) observou que algumas espécies de peixes de fecundação externa apresentavam maior proporção de machos durante o ciclo reprodutivo, mas grande parte das fêmeas apresentava altos índices de fecundidade. Esse comportamento traria grandes vantagens, pois os machos poderiam fecundar um maior número de ovócitos, aumentando as chances de perpetuação da espécie. O autor também evidencia que fatores de pressão ambiental podem deslocar essa proporção de machos e fêmeas, deslocando positivamente ou negativamente a efetividade da espécie no ambiente.

Para A. scabripinnis, é possível sugerir que isso seja um ajuste às condições locais em conjunto com as características de comportamento reprodutivo, demonstrando, de forma geral, uma tendência da espécie à capacidade R estrategista em relação ao ambiente em que vive.

Astyanax scabripinnis paranae parece demonstrar, em sua biologia reprodutiva, grande adaptação ao tipo de ambiente em que vive, como o de cabeceira de ribeirões pequenos que apresentam grandes e rápidas mudanças na dinâmica hidrológica durante as estações do ano (HaUer \& LAMberTi 1996). A espécie apresentou um elevado esforço reprodutivo e táticas que possibilitam a sua permanência como população nesse tipo de sistema. No entanto, há necessidade de se intensificar os estudo relativos a essa espécie, visto a progressiva degradação das cabeceiras de rios, o que demanda ações imediatas de preservação de $A$. scabripinnis, que está apta a sobreviver nesse tipo de habitat.

\section{AGRADECIMENTOS}

Ao Dr. Heraldo Antonio Britski, pela valiosa orientação no trabalho e identificação da espécie estudada; ao Dr. Oscar Akio Shibatta e ao Dr. Edmir Daniel Carvalho, pelas sugestões dadas, e ao Dr. Ângelo Agostinho, pela assistência neste estudo.

\section{REFERÊNCIAS BIBLIOGRÁFICAS}

Agostinho, C.A.; S.L. Molinari.; A.A. Agostinho \& J.R. Verani. 1984. Ciclo reprodutivo e primeira maturação sexual de fêmeas do lambari, Astyanax bimaculatus Linnaeus, 1758

Revista Brasileira de Zoologia 20 (1): 97-105, março 2003 
(Ostheichthyes, Characidae) do rio Ivaí, Estado do Paraná. Revista Brasileira de Biologia, Rio de Janeiro, 44 (1): 3136.

Arcifa, M.S.; T.G. Northcote \& O. Froehlich. 1991. Interactive ecology of two cohabiting characin fishes (Astyanax fasciatus and Astyanax bimaculatus) in an eutrophic Brazilian reservoir. Journal of Tropical Ecology, London, 7 (2): 257 268.

BALON, E. K. 1984. Patterns in the evolution of reproduction styles in fishes, p. 35-53. In: G.W. Pоттs \& R.J. WootTon (eds). Fish reproduction: strategies and tactics. London, Academic Press, 237p.

BARBIERI, G. 1992. Biologia de Astyanax scabripinnis paranae (Characiformes, Characidade) do ribeirão do Fazzari. São Carlos. Estado de São Paulo. II. Aspectos quantitativos da reprodução. Revista Brasileira de Biologia, São Carlos, 52 (1): 589596.

Barbieri, G.M.; V.R. SANTos \& J.M. SANTos. 1982. Época de reprodução e relação peso/comprimento de duas espécies de Astyanax (Pisces, Characidae). Pesquisa Agropecuária Brasileira, Brasília, 17 (7): 1057-1065.

Barbieri, G.; S.M. Hartz \& J.R. Verani. 1996. O fator de condição e índice hepatossomático como indicadores do período de desova de Astyanax fasciatus da represa do Lobo, São Paulo, São Paulo (Osteichtyes, Characidae). Iheringia, Série Zoologia, Porto Alegre, (81): 97-100.

Bazzoli, N.; T.L. Mesquita; G.B. Santos \& E. Rizzo. 1998. Análise comparativa da reprodução de Astyanax bimaculatus (Pisces, Characidade) nos reservatórios de Furnas, Marimbondo e Itumbiara. BioSystems, New York, 6 (6): 99-112.

Begon, M. \& M. Mortimer. 1990. Life-history strategies, p.115172. In: Population ecology. London, Blackwell Scientific Publications, 548p.

BRAGA, F.M.S. 1990. Contribuição para o conhecimento da reprodução de Moenkhausia intermédia (Characidae, Tetragonopterinae) na represa de Barra Bonita, rio Piracicaba, SP. Naturalia., Rio Claro, 15: 171-188.

Britski, H.A. 1972. Peixes de água doce do estado de São Paulo: sistemática. p.79-108. In: Comissão Inter Estadual da Bacia Paraná-Uruguai. Poluição e piscicultura. São Paulo, Faculdade de Saúde Pública da USP, Instituto de Pesca, 108p.

DAvis, T.L.O. 1977. Reproductive biology of the fresh water catfish. Tandunus tandunus Mitchell, in the Gwydir river, Australia. I. Structure of the gonads. Australian Journal of Marine and Freshwater Reserch, Sydnei, 28 (2): 139-158.

Dias, J.F.; E. Peres-Rios; P.T.C. Chaves \& C.L.B. RossiWongTsChowsKi. 1998. Análise macroscópica dos ovários de teleósteos: problemas de classificação e recomendações de procedimentos. Revista Brasileira de Biologia, São Carlos, 58 (1): 55-69.

Eigenmann, C.H. 1921. The American Characidae. Memoirs of the Museum of Comparative Zoology Harvard, New York, 43: 209-310.

GarutTI, V. 1989. Contribuição ao conhecimento reprodutivo de Astyanax bimaculatus em cursos de água da bacia do rio Paraná. Revista Brasileira de Biologia, Rio de Janeiro, 49 (2): 489-495.

GarutTI, V. \& H.A. BRitsKi. 2000. Descrição de uma espécie nova de Astyanax (Teleostei: Characidae) da bacia do alto rio Para- ná e considerações sobre as demais espécies do gênero na bacia. Comunições do Museu de Ciências e Tecnologia da PUCRS, Porto Alegre, 13: 65-88.

Genari-Filho, O. \& F.M.S. Braga. 1996. Fecundidade e desova de Astyanax bimaculatus e A. schubarti (Characidae, Tetragonopterinae) na represa de Barra Bonita, rio Piracicaba (SP). UNIMAR, Maringá, 18 (2): 241-254.

Godoy, M.P. 1975. Peixes do Brasil: sub-ordem Characaoidei, bacia do rio Mogi-Guaçú. Piracicaba, São Paulo, Editora Franciscana, 847p.

Hauer, F.R. \& G.A. LAMberti. 1996. Methods in stream ecology. San Diego, Academic Press, 673p.

LIson, L. 1960. Histochimie et cytochimie ani: XI males. Paris, Gauthiers-Villars, 842p.

Lobón-Cerviá, J. \& S.T. BenNemann. 2000. Temporal trophic shifts and feeding diversity in two sympatric, neotropical, omnivorous fishes: Astyanax bimaculatus and Pimelodus maculatus in rio Tibagi (Paraná, southern Brasil). Archyve per Hydrobiologye, Stuttgart, 149 (2): 285-306.

Maistro, E.L.; C. Oliveira \& F. Foresti. 2001. Citogenetic characterization of a supranumerary chromosome segment and of B-chromossomes in Astyanax scabripinnis (Teleostei, Characidae). Genetica, New York, 110: 177-183.

Maistro, E.L.; C. Oliveira \& F. Foresti. 2000. Sympatric occurrence of two cytotypes of Astyanax scabripinnis (Characiformes, Characidae). Genetic of Molecular Biology, Ribeirão Preto, 23 (2): 365-369.

Mizoguchi, S.M.H.M. \& I.C. Martins-Santos. 1998. Citogenetic and morphometric differences in populations of Astyanax scabripinnis (Pisces, Characidae) from Maringá region, PR, Brasil. Genetic of Molecular Biology, Ribeirão Preto, 21 (1): 55-61.

Moreira-Filho, O. \& L.A.C. Bertollo. 1991. Astyanax scabripinnis (Pisces, Characidae): a species complex. Revista Brasileira de Genetica, Ribeirão Preto, 14 (2): 331-357.

Nikolsky, G.V. 1969. Theory of fish population dynamics. Edinburgh, Oliver \& Boyd, 323p.

Nomura, H. 1975. Fecundidade, maturação sexual e índice gônadossomático de lambaris do gênero Astyanax Baird e Girard, 1854 (Osteichthyes, Characidae), relacionados com fatores ambientais. Revista Brasileira de Biologia, Rio de Janeiro, 35 (4): 775-798.

Porto-Foresti, F.; C. Oliveira, L.C. Maistro \& F. Foresti. 1997. Estimative of B-chromossome frequency and populacional density of a local population of Astyanax scabripinnis paranae (Pisces, Characidae, Tetragonopterinae). Brazilian Journal of Genetic, Ribeirao Preto, 20: 377-380.

Rincón, P.A. 1999. Uso do micro-hábitat em peixes de riachos: métodos e perspectivas. p. 23-90. In: E.P. CARAmaschi; R. Mazzoni \& P.R. Peres-Neto (eds.). Ecologia de peixes de riachos. Rio de Janeiro, PPGE-UFRJ, Série Oecologia Brasiliensis, vol. 6, XVI+260p.

Souza, I.L. \& O. Moreira-Filho.1995. Cytogenetic diversity in the Astyanax scabripinnis species complex (Pisces, Characidae). I. Allopatric distribution in a small stream. Citologia, São Paulo, 60: 1-11.

UIEDA, V.S. 1984. Ocorrência e distribuição dos peixes em um riacho de água doce. Revista Brasileira de Biologia, São Carlos, 44: 203-213. 
VAZzoler, A.E.M. de M. 1996. Biologia da reprodução de peixes teleósteos: teoria e prática. Maringá, EDUEM, 169p.

Vazzoler, A.E.A.M.; H.I. Suzuki; E.E. Marques \& M.L.A.P. Lizama. 1997. Primeira maturação gonadal, períodos e área de reprodução. p. 97-143. In: A.E.A.M. Vazzoler; A.A. Agostinho \& N.S. HAHN (Eds.) A planície de inundação do alto Rio Paraná: aspectos físicos, biológicos e socioeconômicos. Maringá, EDUEM, 460p.

Recebido em 08.VIII.2002; aceito em 03.III.2003.
WEST, G. 1990. Methods of assessing ovarian development in fishes: a review. Australian Journal of Marine and Freshwater Reserch, Sydnei, 41: 199-222.

Winemiller, K.O. 1989. Patterns of variation in life history among South American fishes in seasonal environmentals. Oecologia, Paris, 81: 225-241.

Wootton, J.R. 1998. Ecology of teleost fishes. New York, Kluwer Academic Publishers, $2^{\text {nd }}$ ed., 386p. 